\title{
Improving the design of hydraulic cylinders used in hydraulic equipment for irrigation and drainage
}

\author{
Yevgeniy Slivinskiy ${ }^{1}$, Sergey Radin $^{1, *}$ \\ ${ }^{1}$ Yelets State University Named After I.A. Bunin, 28, str. Kommunarov, 399770, Yelets, Lipetsk \\ Oblast, Russia
}

\begin{abstract}
The purpose of work - development of practical recommendations for modernization of hydraulic cylinders, widely used in irrigation and drainage and other agricultural equipment design created at the invention level (RU2702205) and the calculations to substantiate its basic geometric parameters. Research methods - to achieve the goal, a modern method of calculating the forces created by the magnetic fields of permanent magnets used in sealing devices of hydraulic cylinder rods was used; practical recommendations are given on the need to use such devices in practice. Research results and novelty - research results are recommended by both domestic and foreign research institutes, design and production structures of agricultural engineering for further study, refinement and its possible practical implementation. Conclusions analyzing the proposed directions for the modernization of sealing devices of hydraulic cylinder rods, it can be concluded that the developed technical solution allows to increase the operational reliability of hydraulic equipment not only for irrigation and drainage, but also for other purpose of agricultural machinery.
\end{abstract}

\section{Introduction}

Now, in practice, irrigation and drainage machines of various designs are widely used, and in particular, bulldozers, which are self-propelled earth-moving equipment intended mainly for cutting, planning and moving soil and materials to distance of up to 150 meters. Typically, bulldozers consist of base tractor or truck, in front of which there mounted a working body in the transverse plane - a blade (Figure 1). The most widespread are bulldozers with fixed blade, with rotary blade, bulldozer with pneumatic ripper and bulldozers loaders [1,2]. The position of blades is controlled by various constructed hydraulic cylinders [3-5].

In the general case, such a hydraulic cylinder (Figure 2) consists of housing 1, rod 2 located in cover 3 with o-rings and carrying piston 4 . Despite the operation efficiency of such hydraulic cylinder, it has an important drawback, namely, that the o-rings have insufficient durability due to the inability to change the force of its contact with the rod. As a result, the latter require repair work on the replacement of o-rings (Figure 2) [6-7].

\footnotetext{
*Corresponding author: radin81@mail.ru
} 


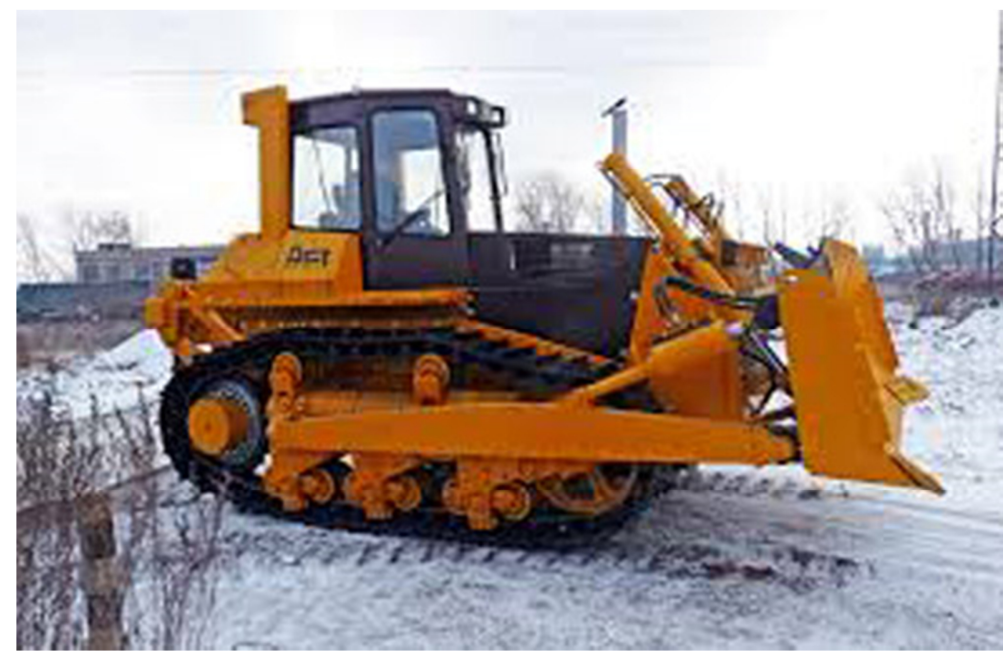

Fig. 1. General view of a bulldozer.

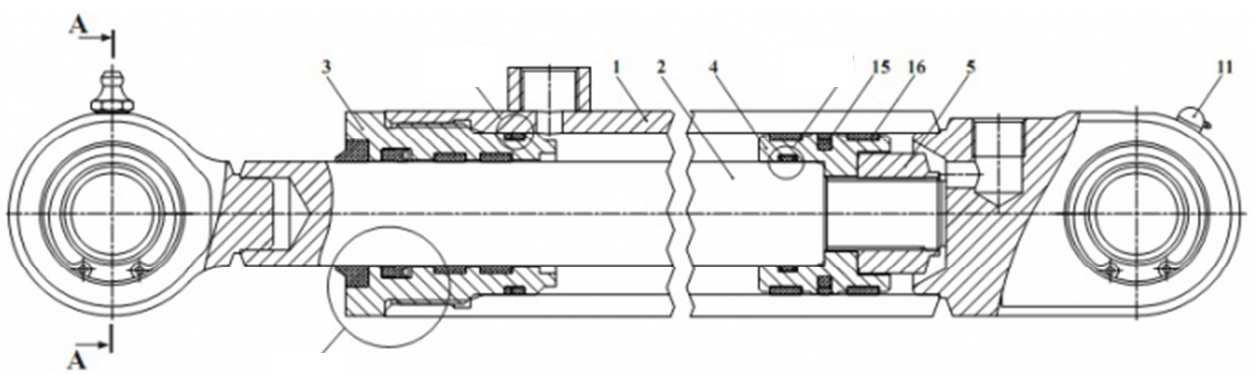

Fig. 2. Basic diagram of a hydraulic cylinder.

It should also be noted that similar designs of hydraulic cylinders have also found widespread use not only in agricultural machinery, material handling equipment, metalworking equipment, construction production, etc. Moreover, the latter are included in the hydraulic structures and schemes of such machines, called hydraulic systems. Typically, hydraulic drive, for example, on the above-described bulldozer, includes a pump, drive for which is the machine engine and the piping system connecting it to the control valve, filter, hydraulic tank and hydraulic cylinders. In practice, mainly hydraulic gear machines are used as pumps, which have different sizes and volumetric flows, and VMGZ and MG-30 liquid mineral oils are used as working fluid, which are simultaneously lubricating and anticorrosion media for units and hydraulic systems [8-15].

Based on the abovementioned, it is clear that all known hydraulic cylinder designs today do not meet the modern requirements for reliable operation of the latter, and therefore the task of ensuring its durability is very urgent.

\section{Methods}

Considering the importance of such problem, at «Student Design Bureau of Yelets State University named after I.A. Bunin», Department «Technological Processes in Mechanical Engineering and Agricultural Engineering» ppplied research work is being conducted on the development and improvement of road-building and agricultural machinery construction, including bulldozers. 
As a result of the analysis of numerous literary sources, as well as domestic and foreign patents, it was possible to develop a promising sealing device for hydraulic cylinder rods, which has sufficiently high durability, recognized by the invention (patent RU2702205 Hydraulic cylinder, by the authots: Slivinskiy Y.V., Radin S.Y., Shatskiy A.V.)

This design of the hydraulic cylinder differs from previously known. In the cover of the cylinder housing, made of diamagnetic material, coaxial to piston rod, there installed the magnetic ring, contacting through an air gap with another, the same magnetic pole of another, but dissected ring of smaller, than the first one, diameter and having on its inner generatrix the surfaces of appropriate sizes of projections and troughs of rectangular cross section, in which there placed protrusions and troughs of the ring made of elastic material. Moreover, the inner surface of the latter has cylindrical shape and interacts with counter surface of the piston rod.

So, at the Figure 3 there shown a part of the hydraulic cylinder from fastening side to its cover body and its cross section with transverse plane with a notch.

Such hydraulic cylinder consists of housing 1 , cover 3 and pressure washer 4 are attached, using bolts 2 . In the cover 3, there rigidly fixed a ring 5 made of magnet, which through the air gap $\delta$ adjacent to one of the moving parts of dissected magnetic ring 6 and it has protrusions 8 and troughs 9 with protrusions placed in it 10 of rubber ring 11 covering rod 12 of the hydraulic cylinder.
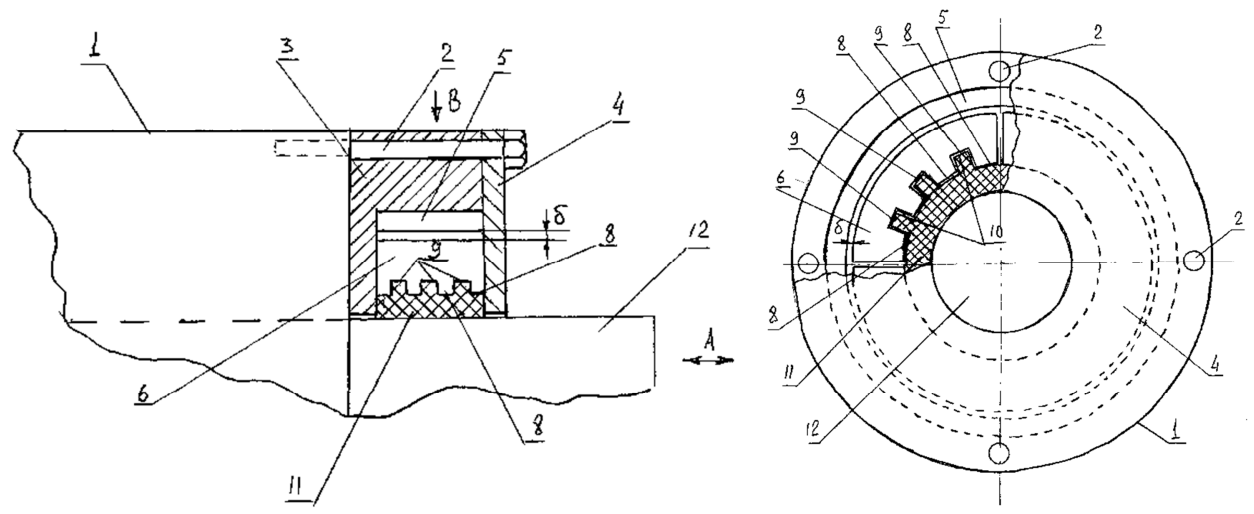

Fig. 3. Rod sealing device by the patent RU2702205.

The hydraulic cylinder operates as follows. When working fluid is supplied under pressure from hydraulic power station due to the piston presence in the hydraulic cylinder (it is not shown at Figure 3) its rod 12 can move along arrows A (Figure 3) performing certain work of the actuator to which it is connected to. This rod movement 12 occurs with slip of its circular surface on inner surface of rubber ring 11, eliminating working fluid leakage through the cover 3 of the housing 1 of the hydraulic cylinder. Reliable contact of rubber ring 11 with rod 12 provided by the fact, that the magnetic ring 5 by its same-named magnetic pole acts the air gap $\delta$ to similar magnetic pole of the dissected magnetic ring 6 in the direction of the arrow $B$ thereby constantly pressing the rubber ring 11 to the rod 12 of the hydraulic cylinder evenly distributing the force throughout its entire circular generatrix onto the rod 12. Therefore, such sealing device design is able to reliably prevent the possibility of working fluid leakage from the housing 1 of the hydraulic cylinder through the cover 3 into the environment.

The technical and economic advantage of the proposed development in comparison with known designs of the sealing elements of the hydraulic cylinder rods is obvious, since it makes it possible to more effectively distribute the loads applied to the latter. 
It should be noted that the interaction force between magnetic ring 5 and dissected magnetic ring 6 , in which protrusions 8 and troughs 9 are made, with protrusions 10 of rubber ring 11 covering rod 12 of the hydraulic cylinder, can be determined by the known dependence [16]:

$$
N=\frac{S B^{2}}{2 \mu_{0}},
$$

where $B$-induction in the piston contact zone and the magnetic ring;

$\mu_{0}$ - magnetic permeability;

$S$ - contact area of the magnetic ring.

The required force created by magnetic field onto rubber ring 11 (Figure 3) can be obtained already today. For example, it is known that in Japan at the end of the seventies of the last century, there were created permanent magnets on a polymer basis, from 1 square centimeter of which you can get the adhesion force to metal materials up to $9000 H$ [16]. The use of permanent magnets in manufacture of the proposed technical solution will allow to vary within wide limits the magnetic rings 6 diameters, which ultimately will allow us to tie the proposed design to different purpose cylinders widely used in practice.

We give an example of calculating the indicated sealing device for hydraulic cylinder, recommended by GOST 6540 - 68, which has the following main structural parameters: $D$ case inner diameter of $160 \mathrm{~mm}, d$ piston rod outer diameter of 40 piston rod outer diameter, $t$ piston stroke $200 \mathrm{~mm}$ and working fluid pressure of $10 \mathrm{MPa}$.

To calculate the abovementioned strength $N$ (formula 1) we accept the following initial parameters:

$B$ - induction in the working gap of the magnetic ring 5 and 6 , equal to $1.5 \mathrm{~T}$;

$\mu_{0}$ - air gap magnetic permeability of $4 \pi \cdot 10^{-7} \mathrm{GN} / \mathrm{m}$;

$S$ - contact area of the magnetic ring 5 and 6 .

Define the contact area $\mathrm{S}$ of the magnetic ring 5 with dissected magnetic ring 6 according to: $S=\pi d b=3,14 \cdot 0,0078 \cdot 0,0015=0,000037 \mathrm{~m}^{2}$, where $d=78 \mathrm{~mm}-$ inner diameter of dissected magnetic ring 6 , and $b=15 \mathrm{~mm}-$ its width.

Then numerical value of the force created by the dissected magnetic ring 6 is: $N=$ $\mathrm{SB}^{2} / 2 \mu_{0}=0,000037 \cdot 1,5^{2} / 4 \cdot 3,14 \cdot 10^{-6}=66,98 \mathrm{~kg}=669,8 \mathrm{H}$. It can be seen that the rubber ring 11, mounted on the inner diameter of the dissected magnetic ring 6 supplied by troughs 9 and protrusions 8 (Figure 3), will provide reliable sealing of the cylinder body internal volume from the external environment since it will be constantly and tightly enclose the rod 12 of the hydraulic cylinder with force of $66.98 \mathrm{~kg}$.

It was noted that various pumps were widely used in modern hydraulic units, and gear hydraulic pumps were most widely used (Figure 4).

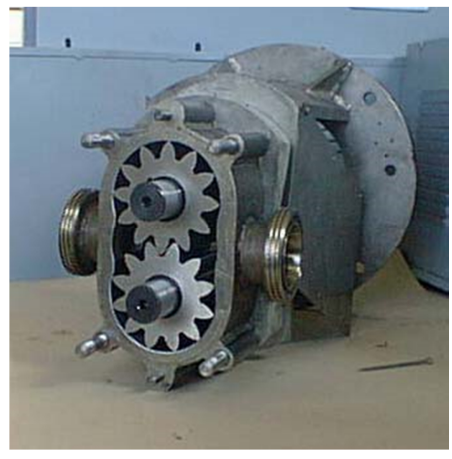

Fig. 4. General form of the gear hydraulic pump. 
Gear hydraulic pumps are the simplest in construction in comparison with all other well-known hydraulic units and are widely used in agricultural units' construction, automobiles, road construction machines, etc. It consists (Figure 4) of a housing in which drive and driven gears are installed. When the drive gear rotates, the working fluid, located in space between wheels' teeth is transported from the suction cavity to the discharge cavity. Gear pumps are mainly used to obtain pressures up to $15 \mathrm{MPa}$, and in some cases up to $210 \mathrm{MPa}$. Significant drawback of such hydraulic units is the high pulsation of the working fluid and low productivity [8-10].

Analysis of many bibliographic sources, domestic and foreign patents, allowed to develop promising constructions of two gear hydraulic units recognized by inventions (RU2338926, RU2341686).
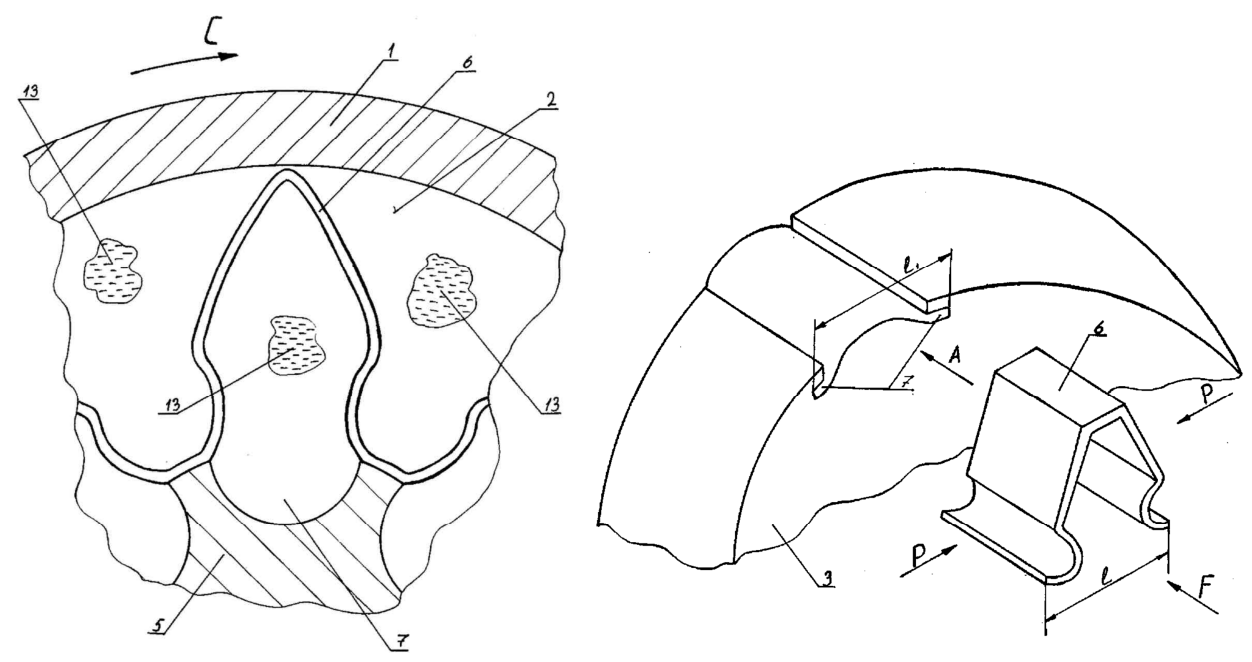

Fig. 5. General view of hydraulic units according to patents RU2338926, RU2341686.

The main difference between such technical solutions from the known gear hydraulic units is that the teeth of the driving and driven gears are hollow, which allows to place an additional significant amount of transported working fluid in it. But since the amount of transported fluid is significantly increasing, in general, its flow will be more uniform and stable in the proposed constructions of hydraulic units. It should also be noted that fluid flow pulsation is also possible as with known units, but its value will be very small and is characterized only by the area created by the tooth heads in the zone of its contact with hydraulic unit body.

The calculations by the known method [11] showed that for the proposed gear hydraulic units, in comparison with the serial, working fluid pulsation decreases by 1.93 times, productivity increases by 1.8 times and its metal consumption, due to the implementation of teeth hollow, and removal of some metal part when milling recesses in the housing in its suction and discharge cavities is lower by an average of $27 \%$.

At the same time, the second proposed gear hydraulic unit (RU2341686) has high maintainability due to the use of removable gear teeth in its construction. Such an innovation will allow in the conditions of repair production to repeatedly repair the pump at the lowest cost. The calculation of economic efficiency from the possible implementation of the development showed that within 5.5 years this project will cover all the costs associated with the introduction of modernized gear hydraulic unit. The study results were transferred to the plant of Eletshydroagregat OJSC management to evaluate the proposed technical solution, manufacture a prototype and test it under bench conditions. At the same 
time, the proposed constructuin of the gear pump is recommended to scientific and production units, both in our country and abroad with a view to its possible use in agricultural engineering practice.

\section{Conclusions}

The research results are recommended by both domestic and foreign research institutes, design and production structures of both domestic and foreign agricultural engineering for further study, refinement and its possible implementation in practice.

\section{References}

1. J.A. Stark, Truck \& Off-Highway Industries 1(2), 51-55 (1979)

2. L.M. Varas Vilachán, Carreteras 4(222), 8-16 (2018)

3. A. Ylinen, H. Marjamäki, J. Mäkinen, Computers \& Structures 138, 62-72 (2014)

4. I. Larchikov, A. Yurov, S. Stazhkov, A. Grigorieva, A. Protsuk, Procedia Engineering 69, 512-517 (2014)

5. I. Marczewska, T. Bednarek, A. Marczewski, W. Sosnowski, H. Jakubczak, J. Rojek, International Journal of Fatigue 28(12), 1739-1751 (2006)

6. W.E. Tomasz Bednarek, International Journal of Fatigue 32(10), 1591-1599 (2010)

7. Z. Zhang, D. Wu, H. Pang, Y. Liu, W. Wei, R. Li, Engineering Failure Analysis 109, 104358 (2020)

8. D. Llorente Rivera, M.R. Scholz, M. Fritscher, M. Krauss, K. Schilling, IFACPapersOnLine 51(11), 447-452 (2018)

9. J.R. Wagner, E.M. Mount, H.F. Giles, Plastics Design Library, Extrusion (Second Edition) (William Andrew Publishing, 2014)

10. R. Doddannavar, A. Barnard, S. Mackay, 3 - Hydraulic pumps, Practical Hydraulic Systems (Newnes, 2005)

11. A.I. Pavlov, I.A. Polyanin, K.E. Kozlov, Procedia Engineering 206, 1629-1635 (2017)

12. K. Yang, S. Guan, C. Wang, Procedia Engineering 16, 418-422 (2011)

13. I. Marczewska, T. Bednarek, A. Marczewski, W. Sosnowski, H. Jakubczak, J. Rojek, International Journal of Fatigue 28(12), 1739-1751 (2006)

14. L. Schmidt, M. Groenkjaer, H.C. Pedersen, T.O. Andersen, Control Engineering Practice 64, 1-14 (2017)

15. K.E. Thomsen, O.G. Dahlhaug, M.O.K. Niss, S.K. Haugset, Energy Procedia 24, 76-82 (2012)

16. H. Sepehri-Amin, S. Hirosawa, K. Hono, Elsevier 27, 269-372 (2018) 